\title{
The influence of conformation on fore and hind limb kinematics of the trotting Dutch Warmblood horse
}

\author{
W. Back', H. C. Schamhardt² and A. Barneveld \\ ${ }^{1}$ Department of General and Large Animal Surgery, Utrecht University, The Netherlands \\ 2Department of Veterinary Anatomy, Utrecht University, The Netherlands
}

\begin{abstract}
Summary
To objectively evaluate the influence of conformation on equine kinematics a study was undertaken in which joint angles of horses at square stance representing conformation were related to their limb kinematics at the trot. A modified CODA-3 apparatus was used to record joint angles of a group $(n=24)$ of young adult Dutch Warmblood horses at square stance and at the trot on a treadmill. It appeared that the forelimb of horses with a more horizontal scapula moved in a more protracted position. This compares with a more elegant gait in dressage horses and a more efficient forelimb technique in showjumpers. More flexed shoulder and elbow joints were related to a longer stance duration facilitating collection in the forelimbs. A more vertical pelvis and a more flexed hip and stifle joints induced less retraction and more pelvic rotation, leading to more collection in the hind limbs. However, a more extended carpal and tarsal joint resulted in more extension of these joints during the stance phase. This predisposes for joint overloading, which eventually may result in lameness and early retirement of the performance horse.
\end{abstract}

Keywords: $\quad$ equine, conformation, gait, lameness, performance

Der Einfluß des Exterieurs auf die Bewegung der Vorder- und Hintergliedmaßen des Niederländischen Warmblutpferdes im Trab

Um den Einfluß des Exterieurs von Pferden auf ihre Bewegungen objektiv zu beurteilen, wurden in dieser Studie die Gelenkwinkel von Pferden beim gleichmäßigem Stand auf vier Füßen bei der Exterieurbeurteilung in Beziehung gesetzt zu ihren Gliedmaßenbewegungen im Trab. Mittels eines modifizierten CODA-3 Apparates wurden die Gelenkwinkel einer Gruppe von 24 Niederländischen Warmblutpferden im Stehen auf vier Füßen und im Trab aufgezeichnet. Die Vordergliedmaßen von Pferden mit einem mehr horizontal gelagerten Schulterblatt wurden weiter vorgeführt. Dies geht bei Dressurpferden einher mit einem eleganteren Gang beziehungsweise mit einem effizienteren Einsatz der Vorderbeine bei Springpferden. Gebeugtere Schulter- und Ellbogengelenke bewirkten eine längere Stützphase, dies erleichterte die Versammlung im Bereich der Vordergliedmaßen. Eine vertikalere Stellung des Beckens und gebeugtere Hüft- und Kniegelenke führten zu weniger Rückführung der Hintergliedmaßen und mehr Beckenrotation, somit zu mehr Versammlung in der Hinterhand. Gestrecktere Karpal- und Tarsalgelenke bewirkten eine größere Streckung dieser Gelenke in der Stützphase. Dieses prädisponiert zur Überlastung der Gelenke, die eventuell zu Lahmheit und früher Unbrauchbarkeit von Sportpferden führen kann.

Schlüsselwörter: Pferd, Exterieur, Gang, Lahmheit, Leistung

\section{Introduction}

Apart from quality of gait and genetic background of performance, conformation judging is one aspect in the selection of equine athletes (Oliver and Langrish 1992). Conformation largely determines the general appearance of the horse. Furthermore, it is assumed to be indicative for future riding performance of the warmblood horse in dressage and jumping, and is used to select horses with a lower risk for developing lameness (Knopfhart 1966, Strickland 1992). Although selection procedures have been extended with free jumping and a standardized 70-day performance test with a differentiation in dressage and jumping, conformation still is the basis of judging young stallions at the studbook sales.

Little objective data is available to support the value of conformation as a predictor of performance (Koenen et al. 1995), or as a predisposing factor in the development of lameness (Stashak 1987). Moreover, only one study was done, in which morphometrics were directly related to overground kine- matics in 6-8 month-old male Quarter horse foals locomoting overground at their own preferred speed on well-packed snow (Leach and Cymbaluk 1986).

The present study was undertaken to objectively evaluate the relationship between conformation and kinematics of riding horses at the trot recorded under standardized conditions at the age when they normally are selected by the studbook.

\section{Materials and methods}

\section{Horses}

Twenty four Dutch warmblood horses (11 stallions and 13 geldings) were kept at standardized housing and feeding conditions after weaning at the age of 3 months. The stallions were castrated at the age of 10 months. The total group of horses was trained to walk, trot and canter on a treadmill. At the age of 26 -months recordings took place; at that time the mean height at the withers 
of the group of 24 horses was $161.5 \mathrm{~cm}(151.2-174.0 \mathrm{~cm})$ and the mean weight $540 \mathrm{~kg}$ (range 463-638 kg).

\section{Markers}

At palpable anatomical landmarks marker holders were glued to the skin, as described in detail before (Back et al. 1994). In the forelimb three were attached to the hoof: No. 1 to the heel, No. 2 to the toe and No. 3 to the coronary band. No. 4 and No. 5 were glued to the distal and proximal metacarpus, No. 6 and No. 7 to the distal and proximal radius, No. 8 and No. 9 to the distal and proximal humerus, No. 10 and No. 11 to the distal and proximal spina scapula. In the hind limb the markers on the distal limb were at similar locations as in the forelimb. No. 6 and No. 7 were glued to the distal and proximal tibia, No. 8 and No. 9 to the distal and proximal femur and No. 10 to the tuber coxae.

\section{Recording equipment}

A modified CODA-3 apparatus was placed perpendicular to the left side of the treadmill at a distance of 8-10 $\mathrm{m}$. The scanner emitted three mutually synchronized planar light beams at a frequency of $300 \mathrm{~Hz}$ : two were vertically focused and rotated horizontally, and one was focused horizontally rotating vertically. These light beams were detected by the passive photodiode markers. In-built preamplifiers translated the light into electrical signals, which were sent to a computer via a terminal fixed to the girth strap and an "umbilical cord". The timing at which a particular light pulse was detected was converted into the angle between the light beam and the CODA scanner. From the three angles of the three bundles, the computer calculated the $X, Y$ and $Z$ coordinates of the markers with an accuracy of about 0.3 $\mathrm{mm}$ in the plane of movement. An accelerometer was glued to the hoof to detect hoof initial ground contact.

\section{Recording procedure}

After a 5 minute warm up the position of the markers representing conformation of the fully equipped horse was recorded during 1 second (300 frames), while it was standing square on the treadmill. Then the trot of the horse was recorded at a speed of $4 \mathrm{~m} / \mathrm{s}$ during 10 seconds (3000 frames). Fore and hind limb motion had to be evaluated in two separate sessions because a maximum of 12 markers could be recorded at the same time.

\section{Data analysis}

From the $X, Y, Z$ coordinates of the markers the angles between the different limb segments were calculated representing joint angles in the sagittal plane at square stance (conformation) and at trot (kinematics): fetlock joint (No. 3,4,5), carpal and tarsal joint (No. 4,5,6,7), elbow and stifle joint (No. 6,7,8,9), shoulder and hip joint (No. 8,9,10,11), and the scapula (No. 9-11) and pelvis (No. 9-10) angle with the horizontal. A larger shoulder, elbow, carpal, hip, stifle, or tarsal joint angle at square stance means a more flexed joint, while a larger fetlock joint means a more extended or dorsi-flexed fetlock joint. A larger scapula or pelvis angle means a more vertical or "inclined" position. Protraction and retraction were defined as the angle between the vertical and a line through the rotation point of the "pendulating" limb and the markers at the coronary band on the hoof using No. 3 and 11 in the forelimb and No. 3 and 10 in the hind limb. The peak in the accelerometer signal when the hoof touched the ground at initial ground contact $(t=0)$ was used to calculate stride duration. The transition from stance to swing phase was kinematically defined as being the moment as to when the fetlock angle reached its angle at initial ground contact again.

\section{Statistics}

Pearson correlation coefficients were calculated between joint angles in the square standing horse and relevant temporal and spatial kinematic variables at the trot at a significance level of $p<0.05$ using the software program Statview ${ }^{\circledR}$ running on an Apple Macintosh LC II computer. Correlation coefficients higher than 0.30 were evaluated to indicate biological tendencies, while above 0.40 they were considered to be statistically significant $(\mathrm{p}<0.05)$.

\section{Results}

Looking at the definition of the joint angles it is not surprising that the angles of adjacent joints at square stance correlated. In the forelimb the scapula angle with the horizontal significantly correlated with the shoulder joint angle $(-0.66)$, and the carpal with the fetlock joint (0.62). In the hind limb the tarsal joint angle of the horse standing square correlated with the stifle and fetlock joint angle (0.49 and -0.36$)$.

\section{Forelimb}

A more horizontal scapula correlated with more maximal protraction and less maximal retraction (Tab. 1). A more flexed elbow joint at square stance corresponded with a longer stance duration. In this respect it was also found that both a more horizontal scapula as well as a more flexed shoulder joint were significantly related to more maximal extension of the elbow joint relative to the angle at initial ground contact $(-0.42,0.48)$. Both carpal and forelimb fetlock joint angle in the square standing horse correlated significantly with the angle at initial ground contact, at maximal extension and at maximal flexion at the trot (Tab. 2). Moreover, a horse having a more extended fetlock joint angle at square stance showed more protraction, more maximal fetlock extension relative to the joint angle at initial ground contact and an increased range of fetlock joint motion.

\section{Hind limb}

At trot maximal retraction and range of maximal pro- and retraction were smaller when the pelvis was more vertical and the stifle joint more flexed at square stance (Tab. 1, 2). A horse standing with a more flexed hip joint showed significantly more pelvis rotation and demonstrated a more flexed hip joint at initial ground contact, at maximal extension and at maximal flexion at the trot. Also the tarsal and hind limb fetlock joint angle in the square standing horse correlated significantly with the joint angle at initial ground contact, at maximal extension and at maximal flexion at the trot. However, a horse with a more flexed tarsal joint showed less flexion relative to the angle at initial ground contact, and a decreased range of tarsal joint motion and of maximal pro- and retraction. Horses with a more straight tarsal or hind limb fetlock joint showed longer stride and swing durations. The hind limb fetlock joint angle at square stance correlated, like in the forelimb, with maximal protraction and with the range of maximal pro- and retraction.

\section{Discussion}

Apparently, conformation variables calculated from the joint angles of horses standing square correlated with kinematic varia- 
Tab. 1: Correlation coefficients of conformation angles of 24 Dutch Warmbloods standing square and limb kinematics at the trot, for several fore and hind limb variables.

\begin{tabular}{|l|l|l|l|l|l|l|l|l|l|l|}
\hline & \multicolumn{5}{|c|}{ Forelimb } & \multicolumn{4}{c|}{ Hind limb } \\
\hline Limb kinematics & Scapul & Shoulder Elbow & Carpus & Fetlock & Pelvis & Hip & Stifle & Tarsus & Fetlock \\
\hline Stride duration (s) & 0.18 & -0.03 & -0.17 & 0.12 & 0.02 & 0.01 & -0.14 & -0.19 & -0.32 & -0.40 \\
\hline Stance duration (\%) & 0.03 & 0.17 & $0.60^{*}$ & -0.05 & 0.13 & -0.18 & 0.24 & 0.03 & 0.38 & $0.41^{*}$ \\
\hline Swing duration (\%) & -0.03 & -0.17 & $-0.60^{*}$ & 0.05 & -0.13 & 0.18 & -0.24 & -0.03 & -0.38 & $-0.41^{*}$ \\
\hline Stance duration (s) & 0.23 & 0.15 & $0.44^{*}$ & 0.08 & 0.17 & -0.21 & 0.14 & 0.18 & 0.10 & 0.06 \\
\hline Swing duration (s) & 0.11 & -0.10 & -0.38 & 0.10 & -0.04 & 0.09 & -0.19 & -0.14 & -0.38 & $-0.44^{*}$ \\
\hline Scapula rotation (deg) & -0.08 & 0.14 & 0.17 & -0.30 & -0.24 & -0.19 & $0.43^{*}$ & -0.11 & -0.08 & 0.01 \\
\hline Max protraction (deg) & -0.39 & 0.07 & 0.05 & 0.27 & $0.45^{*}$ & 0.02 & 0.02 & 0.07 & -0.21 & $0.52^{*}$ \\
\hline Max retraction (deg) & 0.33 & 0.08 & 0.24 & -0.29 & -0.11 & $-0.45^{*}$ & -0.01 & $-0.50^{*}$ & -0.23 & -0.03 \\
\hline Pro/re range (deg) & -0.06 & 0.01 & 0.24 & -0.01 & 0.31 & $-0.42^{*}$ & 0.01 & $-0.43^{*}$ & -0.39 & 0.39 \\
\hline * $<<0.05$ & & & & & & & & & & \\
\hline
\end{tabular}

Tab. 2: Correlation coefficients of conformation angles of 24 Dutch Warmbloods standing square and joint kinematics at the trot, for several fore and hind limb variables ( $\max$ flex rel to i.g.c. = maximal joint flexion relative to the joint angle at initial ground contact).

\begin{tabular}{|l|l|l|l|l|l|l|l|}
\hline & \multicolumn{3}{|c|}{ Forelimb } & \multicolumn{5}{c|}{ Hind limb } \\
Joint kinematics & Elbow & Carpus & Fetlock & Hip & Stifle & Tarsus & Fetlock \\
\hline Angle at i.g.c. (deg) & 0.29 & $0.79^{*}$ & $-0.83^{*}$ & $0.64^{*}$ & 0.31 & $0.57^{*}$ & -0.34 \\
\hline Max extension (deg) & -0.07 & $-0.75^{*}$ & $0.85^{*}$ & $-0.69^{*}$ & -0.33 & $-0.62^{*}$ & $0.53^{*}$ \\
\hline Max ext rel to i.g.c. (deg) & 0.25 & 0.25 & $0.53^{*}$ & -0.27 & -0.08 & 0.08 & 0.31 \\
\hline Max flexion (deg) & 0.08 & 0.38 & $-0.55^{*}$ & $0.65^{*}$ & -0.01 & -0.01 & -0.18 \\
\hline Max flex rel to i.g.c. (deg) & -0.17 & 0.04 & 0.17 & 0.12 & -0.37 & $-0.45^{*}$ & -0.05 \\
\hline Range of motion (deg) & 0.03 & 0.12 & $0.44^{*}$ & -0.22 & -0.36 & -0.35 & 0.10 \\
\hline
\end{tabular}

${ }^{*} p<0.05$

bles of the same horses recorded at the trot under standardized conditions. The trot at $4 \mathrm{~m} / \mathrm{s}$ was the fastest symmetrical gait at which all the horses demonstrated a comfortable, though demanding trot. Therefore this speed was chosen being the optimal representative of the locomotion of the individual horses to relate limb conformation to kinematics.

In general, when the angle at square stance correlates with the angle at initial ground contact, and at maximal extension (and sometimes even at maximal flexion), the curve in the joint angletime diagrams of different horses is shifted over the $Y$ axis in case of a different conformation. When also the joint angle relative to initial ground contact is influenced by the joint angles at square stance, conformation seems to have a functional effect on locomotion. In the following part of the discussion the correlation results between joint angles at square stance representing limb conformation and limb kinematics at the trot will be compared with what is known in literature about this relationship and level of performance on one hand, and risk of lameness on the other hand.

Scapula, shoulder and elbow joint

Apparently, a more horizontal scapula induces the forelimb to pendulate in a more protracted position, so more in front of the body, which gives more room to saddle and rider (Bennett 1992,
Holmström et al. 1990, Knopfhart 1966, Strickland 1992). In this way dressage horses have a more aesthetic appearance, and enable showjumpers to demonstrate an improved forelimb technique. Retrospective studies in dressage horses and showjumpers indeed showed that a more horizontal scapula is related to a higher level of performance (Holmström et al. 1990, Langlois et al. 1978, Koenen et al. 1995). However, horses with a more vertical position of their scapula and a more straight shoulder joint will suffer more concussion at landing and thus are at higher risk to develop lameness (Holmström and Philipsson 1993, Slade et al. 1975). It is also known that good gait and collection of performance horses is associated with a longer stance duration in the forelimb (Back et al. 1994, Clayton 1994, Holmström et al. 1995). Horses with a more horizontal scapula or a more flexed shoulder joint, showed more maximal extension of the elbow joint relative to the angle at initial ground contact. In these horses it takes longer time when trotting at the same velocity, for the elbow joint to reach maximal extension. Together with a more flexed elbow joint at square stance this results in a longer stance duration improving gait quality with more collection in the forelimbs.

\section{Carpal joint}

Carpus conformation at stance correlated with the carpal joint angle in the trotting horse at initial ground contact and at maximal 
extension. The reason for not wanting horses "back at the knee" is obviously to reduce the risk of hyperextending the carpus at the stance phase and develop chip fractures or carpal palmar ligament damage (Stashak 1987).

\section{Fetlock joint - forelimb and hind limb}

A more extended fetlock joint resulted in more maximal extension which is correlated with good gait in the forelimb (Back et al. 1994, Slade et al. 1975). In the hind limb, however, the fetlock joint angle correlated with temporal kinematics. A more straight hind limb fetlock joint was related to longer stride and swing durations, which are also good gait variables (Back et al. 1994). So, the difference in basic function of the forelimbs and hind limbs in equine locomotion can be illustrated nicely in fetlock joint motion: the forelimb fetlock as a supple strut and the hind limb fetlock as an exponent of impulse (longer swing with same stance duration). Nevertheless, in both fore and hind limbs a more extended fetlock joint is related to more protraction. Marker no. 3 is the distal marker in the definition of both fetlock and protraction angle. When the fetlock joint is more extended, marker no. 3 will be situated more cranially and thus the protraction angle will be larger.

\section{Tarsal joint}

Like for the carpal joint the tarsal joint angle at square stance also dictated the joint motion at the beginning of the stance phase. A more flexed tarsal joint at square stance appeared more flexed during the stance phase, which is wanted to damp concussion and thus to prevent the hind limb from developing spavin (Schauder 1952, Stashak 1987). However, a more straight tarsal joint was related to longer stride and swing durations, and an increased range of tarsal joint motion and thus of maximal pro- and retraction, which improves gait quality (Back et al. 1994, Holmström et al. 1990). On the other hand, this conformation should prevent the hind limb from developing curb (Stashak 1987).

\section{Pelvis, hip and stifle joint}

Good riding horses should have a more inclined pelvis (Knopfhart 1966, Langlois et al. 1978, Strickland 1992). Apparently, a more vertical pelvis and a more flexed stifle joint resulted in less maximal retraction, which will give the horse the appearance as being more collected in the hind limbs. Collection is related to a less retracted position of the hind limb, while protraction of the hind limbs does not change when horses are trotting more collected (Holmström et al. 1995). Furthermore, a more flexed hip results in a more protracted position at stance, and in a more horizontal position of the femur during swing phase. In this way, the horse can keep its hind limbs more under the body, which is important for collection in dressage and lift off in showjumpers (Holmström et al. 1995, Holmström and Philipsson 1993, Knopfhart 1966, Langlois et al. 1978, Strickland 1992). Apparently, a more flexed hip joint also leads to more pelvis rotation, which corresponds with more motion in the lumbo-sacral joint and suppleness at the loins. Again this is essential for collection and contributes to transmission of the impulse generated by hind limbs to the forelimbs (Bennett 1992).

In conclusion, we found that joint angles representing limb conformation, are associated significantly with certain aspects of equine kinematics at the trot. However, there is no "ideal" conformation, whereas some conformation variables can be beneficial and a disadvantage at the same time. When these specific features are kept in mind, evaluation of conformation can be predictive to se- lect horses with a better gait and to detect horses with an increased risk to develop lameness.

\section{References}

Back, W., Barneveld, A., Bruin, G., Schamhardt, H. C. and Hartman, $W$. (1994): Kinematic detection of superior gait quality in young trotting warmbloods. Vet Quart 16, S91-S96.

Bennett, D. (1992): Principles of conformation analysis, volume I, II, III. Fleet Street Publishing Co., Gaithersburg, USA.

Clayton, H. M. (1994): Comparison of the stride kinematics of the collected, working, medium, and extended trot in horses. Equine Vet J 26, 230-234.

Holmström, M. and Philipsson, J. (1993): Relationships between conformation, performance and health in 4-year-old Swedish Warmblood riding horses. Livestock Production Science 33, 293-312.

Holmström, M., Magnusson, L.-E. and Philipsson, J. (1990): Variation in conformation of Swedish Warmblood horses and conformational characteristics of elite sport horses. Equine Vet J 22, 86-93.

Holmström, M., Fredricson, I. and Drevemo, S. (1995): Biokinematic effects of collection on the trotting gaits in the dressage horse. Equine Vet J 27, 281-287.

Knopfhart, A. (1966): Beurteilung und Auswahl von Reitpferden. Paul Parey, Berlin und Hamburg - Zweiter Auflage.

Koenen, E. P. C., Veldhuizen, A. E. van, and Brascamp, E. W. (1995): Genetic parameters of linear scored conformation traits and their relation to dressage and showjumping performance in the Dutch Warmblood riding horse population. Livestock Production Science 43, 85-94.

Langlois, B., Froidevaux, J., Lamarche, L., Legault, C., Legault, P., Tassencourt, L. and Théret, M. (1978): Analyse des liaisons entre la morphologie et l'aptitude au galop au trot et au saus d'obstacles chez le cheval. Ann Génét Sél Anim 10, 443-474.

Leach, D. H. and Cymbaluk, N. F. (1986): Relationships between stride length, stride frequency, velocity and morphometrics in foals. Am J Vet Res 47, 2090-2097.

Oliver, R. and Langrish, B. (1992): A photographic guide to conformation. Allen \& Co, London.

Slade, L. M., Grau, R. B. and Barbalace, R. C. (1975): The influence of conformation on concussive forces in horses. Proc 4th Equine Nutrition and Physiol Symp, Pomona, California, 131-143.

Schauder, W. (1952): Die besonderen stoßbrechenden Einrichtungen an den Gliedmaßen des Pferdes, in angewandt-anatomischer Hinsicht. Dtsch Tierärztl Wschr 59, 35-38.

Stashak, T. S. (1987): The relationship between conformation and lameness. In: Adams' Lameness in horses 4th ed. Lea \& Febiger, Philadelphia, 71-99.

Strickland, C. (1992): The warmblood guidebook. Half Halt Press, Middletown, USA

\section{Acknowledgements}

We gratefully thank Ed de Heer, DVM, and Han Kingma, DVM, for their literature review.

\section{W. Back, DVM, PhD}

Dept. of General and Large Animal Surgery

P.O. Box 80.153

NL-3508 TD Utrecht

The Netherlands

tel. ${ }^{* * 31-30-2531350}$

fax **31-30-2537970

email: w.back@hk.dgk.ruu.nl 